\title{
Management of Steroid Sensitive Idiopathic Nephritic Syndrome in Children
}

\author{
GM UDDIN
}

Summary:

Minimal change disease has become synonymous with steroid sensitive nephrotic syndrome as most of them achieve remission with corticosteroid therapy. Nephrotic syndrome is a common chronic disorder in children characterized by minimal change disease in majority. Despite being one of the most common renal conditions encountered in paediatric practice significant questions regarding treatment remain unanswered. Recent data from reviews shows that increased duration (3-6 months) of prednisolone compared with 2 months significantly reduced risk of relapse for the initial episode. Remission

Steroid sensitive nephrotic syndrome (SSNS) is considered a relatively benign condition, as progression to end stage renal failure is extremely rare and approximately $80 \%$ of child will enter long term remission. ${ }^{1,2}$

Idiopathic nephrotic syndrome in childhood is diagnosed by the presence of significant proteinuria. hypoalbuminaemia and oedema, the underlying cause of which is unknown and minimal changes on renal biopsy by light microscopy. No immunoglobulin (Ig) or complement fraction deposit is seen on immunofluorescence examination.

Minimal change disease has become synonymous with steroid sensitive nephrotic syndrome as renal biopsy is not usually performed when the patient responds to corticosteroids.

However some patients who responds to corticosteroids shows diffuse mesangialproliferation or focal and segmental glomerulosclerosis (FSGS). Moreover, in the early stages, FSGS and minimal change disease are. ${ }^{2,3}$

The annual incidence in the west is about 3 new cases per 100,000 child population, Asians have a higher incidence, about 16 new cases per 100,000 child population. ${ }^{4}$

Address of Correspondence: Prof. Golam Muin Uddin, Professor of Paediatric Nephrology, BSMMU, Dhaka

Received: 8 August, 2005

Accepted: 31 August, 2006 of proteinuria following corticosteroid therapy has greater prognostic value, in relation to long term outcome, then the precise renal histology. In relapsing SSNS prolong prednisolone treatment, daily prednisolone during infections, significantly reduced risk of relapse. Treatment with levamisole, cyclophosphamide, cyclosporine and mycophenolate mofetil is beneficial in valuable proportion of patients. Prospective trials are necessary to identify effective and safe therapies for frequently relapsing and steroid dependent patients.

(J Bangladesh Coll Phys Surg 2007; 25 : 38-42)

The nephrotic syndrome is 15 times more common in children than adults. ${ }^{5}$ Although there is no available local data, it is felt that the incidence in Bangladesh is also higher than in the west. The cause of SSNS is unknown, although the prevalence is higher in atopic families and abnormalities of the cell function. ${ }^{6,7}$ The albumin leak may be the consequence of loss of anionic changes in the glomerular basement membrane.

The nephrotic syndrome is characterized by massive protenuria $\left(3+\right.$ or $4+$ protein or $40 \mathrm{mg} / \mathrm{m}^{2} / \mathrm{hr}$ or $50 \mathrm{mg} / \mathrm{kg} / \mathrm{d}$ ) hypoabuminemia $<25 \mathrm{~g} / \mathrm{dl}$ and oedema. Hyperlipidaemia is invariably present. Urinary Protein $3+/ 4+$ (on dipstick or boiling test) is adequate for defining nephrotic range proteinuria, precise quantification with 24 hours protein in urine is not required for diagnosis. There is excellent correlation with the early morning urine protein (or albumin/createnine ratio of exceeds $200 \mathrm{mg} / \mathrm{m}$.mol in nephrotic patient. ${ }^{8}$ Timed urine collections are difficult in children.

\section{Definitions: ${ }^{9}$}

Remission: Protein free urine (urine protein negative or trace or $<4 \mathrm{mg} / \mathrm{m}^{2}$ /hour for 3 consecutive days).

Relapse: Urinary protein excretion $>40 \mathrm{mg} / \mathrm{m}^{2} /$ hour or urine Albustix $=++$ or more for 3 consecutive days, having previously been in remission. 
Frequent relapse: Two or more relapses within 6 months of initial response or 4 or more relapses within any 12 month period

Steroid dependence: Two consecutive relapses occur during corticosteroid treatment or within 14 days after its cessation.

Steroid resistance: Failure to achieve remission in spite of 4 weeks of standard prednisolone therapy.

\section{Investigations at Initial Presentation}

a) Full blood count, blood levels of albumin, Cholesterol.

b) Renal profile: urea \& creatinine.

c) Blood level of antistreptolysin $\mathrm{O}$ and $\mathrm{C}_{3}$.

d) Urinalysis and Quantification for urinary protein excretion and culture and sensitivity

e) X-ray chest, Montaux test, Hepatitis B surface antigen.

Other investigations depends on the clinical features and the physician in charge.

The international study of kidney Disease in children (ISKDC) had found that at the initial presentation of children with minimal change nephrotic syndrome. ${ }^{10}$

- $20.7 \%$ of children had systolic blood pressure above 98th percentile for age ,

- $22.7 \%$ had microscopic haematuria,

- $32.5 \%$ had transiently raised plasma creatinine concentration.

\section{Management:}

Of the oedematous state:

A. Bed rest: This is not required unless the child has grossly oedematous genitalia may restrict his or her activity because of discomfort.

B. Diet: A normal protein diet with adequate calories. Salt intake should be restricted $12 \mathrm{gm} /$ day. If there is malnutrition due to persistent proteinuria then patient should receive $22.5 \mathrm{~g} / \mathrm{kg}$ proteins daily. A reduction of saturated fat is advisable.

C. Antibiotics: Prophylactic of S pneumonia with oral penicillin at doses of $125 \mathrm{mg}$ B.D, or $250 \mathrm{mg}$ B.D till edema persists is prescribed to children. ${ }^{11}$ Pneumococcal vaccine can be considered.

D. Hypovolaemia: Children with nephrotic syndrome can present with hypovolaemia, manifests with abdominal pain, cold peripheries, poor pulse volume, hypotension and haemoconcentration. A rapid infusion of plasma (purified protein fraction) $20 / \mathrm{ml} / \mathrm{kg}$ or more. Salt poor albumin $1 / \mathrm{gm} / \mathrm{kg}$ body weight as $20 \%$ solution over $1-2$ hours followed by frusemide $1-2 \mathrm{mg} / \mathrm{kg} .{ }^{12,13}$

E. Fluid restriction: Is recommended in severe oedema with Respiratory distress and if plasma sodium $<125 \mathrm{moml} / \mathrm{L}(300 \mathrm{ml} / \mathrm{m} 2 /$ day + previous day urine output).

F. Diuretics: Symptomatic grossly oedematous states with salt poor albumin of $20-25 \%$ with frusemide $1-2 \mathrm{mg} / \mathrm{kg}$.Patients requiring higher doses and prolonged duration should be treated with frusemide along with spironolactone (dose $2-4 \mathrm{mg} / \mathrm{kg}$ daily). There is however, danger of fluid overload so child's urine output and blood pressure should be closely monitored.

4. Corticosteroids in Nephrotic Syndrome:

4.1 Initial episode: The intensity of initial treatment may decrease the rate of subsequent relapses. Current evidence suggests that treatment of the initial episode influence the subsequent course of the illness. Various regimes of corticosteroids have been used.

The international study for kidney Diseases in children had originally recommended four weeks each of daily and alternate day steroid therapy, which was almost universally used until recently. ${ }^{14}$

Arbeitsgemeinschaft fur Paediatrische Nephrologic (APN) has shown significant reduction in relapse after initial treatment of $60 \mathrm{mg} / \mathrm{m}^{2} / \mathrm{d}$ for 6 weeks followed by alternate day $40 \mathrm{mg} / \mathrm{m}^{2}$ for 6 weeks. ${ }^{15,16}$

Longer initial steroid regime proposed and studied by Ueda et al, and ksiazek \& Wysznska, Joyantha who showed a 2 year relapse free rate for the long initial prednisolone dose versus $27.5 \%$ for the modified ISKDC regime. ${ }^{17,18,19}$

Long Initial prednisolone regiem:

Prednisolone dosage at: $60 \mathrm{mg} / \mathrm{m}^{2} /$ day (maximum $80 \mathrm{mg} /$ day) for 4 weeks $\& 40 \mathrm{mg} / \mathrm{m}^{2} / 24$ hours for 4 weeks, reduced by $25 \%$ monthly over the next 4 months. ${ }^{17}$

The children in their first episode of SSNS, treatment with prednisolone for at least 3 months result in fewer children relapsing by 12 to 24 months with increases in benefit being demonstrated for up to seven months of treatment compared with two months therapy. ${ }^{20}$ 
The choice of using either regime left to the individual attending paediatrician.

A child with nephritic syndrome who fails to respond to initial four-week treatment with corticosteroids should be referred to a paediatric nephrologist for renal biopsy.

Relapse: A relapse is defined by albumin excretion of $>40 \mathrm{mg} / \mathrm{m} 2 / \mathrm{hr}$ or urine dipsticks of $2+$ or more for 3 consecutive days.

Treatment of relapse: The ISKDC proposed that relapsing and steroid dependent SSNS should be treated with daily prednisolone $60 \mathrm{mg} / \mathrm{m}^{2} /$ day till the child had been in remission for 3 days followed by 4 weeks of prednisolone given 3 consecutive days out of 7 . More recently, alternate day therapy has been preferred. ${ }^{21}$

The risk of relapse was significantly reduced if children are treated for 7 months compared with modified ISKDC regimen. ${ }^{19,20}$

Frequent relapses and steroid dependence:

In initial responder who has 2 or more relapses within 6 months of initial response or 4 or more relapses in any 12 months period is said to be have frequent relapses.

Reinduction of any relapse with corticosteroids as before and after 4 weeks, dose is tapered to continue alternate day of $0.5 \mathrm{mg} / \mathrm{kg}$ or lower up to 7 months. The number of children with frequent relapse are also decreased with a longer initial course of prednisolone. The relative risk decreased by 0.133 (13\%) for every additional month of treatment up to 7 months. ${ }^{22}$

Alternative treatment:- (Non-Steroidal therapies)

There is not complete agreement about the precise stage at which alternative treatment to corticosteroid should be introduced. It is not necessary to perform renal biopsy at this situation.

Alternative treatment for SSNS should be considered in the following circumstances:

1. Relapse on prednisolone dosage $>0.5 \mathrm{mg} / \mathrm{kg} /$ alternate day plus one or more of the following:

a) Unacceptable side effects of corticosteroid treatment.

b) High risk of toxicity -boys approaching puberty or diabetes.

c) Unusually severe relapses: hypovolaemia or thrombosis and d) In adequate facility for follow up about complication.

2. Relapse on Prednisolone $>1 \mathrm{mg} / \mathrm{kg} /$ day. $^{12}$

Other immunomodulators are recommended. ${ }^{23,}$ 24, 25

(a) Levamisole: Levamisole is an immunomodulating agent which induces remission in $30 \%$ as first steroid sparing agent and $66 \%$ in post cyclophosphamide steroid dependency. Dose is $2-2.5 \mathrm{mg} / \mathrm{kg}$ on alternate day for 12-24 months. Side effects of levamisole are leukopaenia and flu like symptoms, gastrointestinal effects and occasionally vasculities. So, leukocyte count should be monitored every 48 weeks. ${ }^{26}$

Treatment with prednisolone $1.5 \mathrm{mg} / \mathrm{kg}$ on alternate days is continued along with. The dose of prednisolone is gradually reduced by 0.150 .25 $\mathrm{mg} / \mathrm{kg}$ every 4 weeks to maintenance dose of 0.25 $\mathrm{mg} / \mathrm{kg}$, which is to be continued for 6 months. The number of relapses reduced to an equivalent extent by levamisole treatment given for 6 months or more or cyclophosphamide given for 8-12 weeks. ${ }^{26}$

(b) Alkylating agents: Alkaylating agents impaired DNA transcription are cyclophosphamide and chlorambucil. Cyclophosphamide is a potent steroid sparing agent, which induces sustained remission in 53\% of children for I year. ${ }^{23,24}$ Indications are, steroid toxicity, severe relapse with hypovolaemia and thrombosis and poor compliance on follow up. If patient relapses on prednisolone $>1 \mathrm{mg} / \mathrm{kg} / \mathrm{day}$ or after steroid toxicity $>0.5 \mathrm{mg} / \mathrm{kg} /$ day alternate day. The dose of cyclophosphamide is $2-3 \mathrm{mg} / \mathrm{kg} /$ day, alternate day a prednisolone $(1-1.5 \mathrm{mg} / \mathrm{kg})$ for 8-12 weeks. A total cumulative dose of cyclophosphamide 168 $\mathrm{mg} / \mathrm{kg}$. Early side effects include bone marrow suppression, alopecia, GI upset and haemorrhagic cystitis. Late: Infertility and malignancy. There were few data on chlorambucil.

Post cyclophosphamide relapse should be treated with prednisolone and second course of cyclophosphamide if one year had relapsed after the first course or with cyclosporine.

(c) Cyclosporin- $\mathrm{A}^{25,26}$ Immunosuppressive a fungal metabolite, modifies $\mathrm{T}$ cell function inhibits release of interleukin 2 from activated $\mathrm{T}$ helper cells. Cyclosporine treatment given in steroid dependent or frequent relapses despite a course of levamisole $2.5 \mathrm{mg} / \mathrm{kg} / \mathrm{day}$. The dose is $4-5$ $\mathrm{mg} / \mathrm{kg} / \mathrm{day}$ B.D for 12-24 month's trough level 
between 50 and $150 \mathrm{gm} / \mathrm{L}$ and alternate day prednisolone $1.5 \mathrm{mg} / \mathrm{kg}$ for 4 weeks and then tapered. The majority of children relapse after cessation of the therapy. Post cyclosporin - A relapse is treated with high dose prednisolone and remission maintained with cyclosporine A with alternate day prednisolone. Adverse effects are children with hypertension, reduced renal function, gum hypertrophy and hersuitism.

(d) Chlorambucil::27 If children did not respond to other immunosuppressive therapy $0.2 \mathrm{mg} / \mathrm{kg} / \mathrm{day}$ of chlorambucil continued for 12 weeks.

\section{Table-II}

Indication for renal biopsy:

Age $<1$ year or $>15$ years at onset

Renal failure at presentation

Macrospic haematuria

Sustained hypertension

Before third line of therapy

Suspected secondary cause of Nephrotic syndrome

Table-III

Indications for referral to Pediatric Nephrologist

1. Onset $<1$ year of age.

2. Nephrotic syndrome with hypertension, persistent microscopic haematuria, Impaired renal function

3. Complications like refractory edema, thrombosis, severe infection, and steroid toxicity.

4. Resistant to steroids

5. Frequently relapsing or steroid dependent nephrotic syndrome.

\section{Management of Complications: ${ }^{27,28}$}

Infection: The most common infectious complications are peritonitis, bacterial sepsis, cellulitis, and pneumonia. Risk factors for infection low IgG, factor $\mathrm{B}$, oedematous state, impaired lymphocyte function and corticosteroid therapy. Causative organisms are pneumococcus, haemophylus, gram negative organisms, staphylococcus. So, broad spectrum antibiotic should be choosen before culture reports are available. Infection should be suspected and detected early and appropriate treatment should be instituted as early as possible. Patients having significant oedema and ascites should receive oral penicillin- $\mathrm{V}$ to prevent pneumococcal infection until remission is induced. Every effort should be made to ensure that the child receives the recommended vaccines. Administration of live vaccine is avoided until steroid therapy has been discontinued for at least 4-12 weeks.

Thrombosis: Thrombotic complications are uncommon but serious in children with nephrotic syndrome. Risk factors for thrombosis are hypovolemia, hyperviscocity, loss of antithrombin III. increase fibrinogen, platelet aggregability, hyperlipidaemia., use of diuretics. Dehydration should be avoided and prompt treatment of infections should be instituted. Diuretics should be avoided as far as possible, deep veins should never be punctured. Thrombosis initially treated with heparin and maintained with warferin for a period of 6 month or longer.

Hypovolaemia: Rapid loss of protein lead to hypovolaemia if accompanied by septicaemia, diarrhoea or injudicious use of diuretics. Hypovolaemia should be rapidly corrected with infusion saline, plasma $(20 \mathrm{ml} / \mathrm{kg})$ or albumin (20 $\%, 1 \mathrm{gm} / \mathrm{kg}$ ) given over $1-2$ hours followed by frusemide $1 \mathrm{mg} / \mathrm{kg}$.

Hypertension: Hypertension 'should be managed with salt and fluid restriction, and if necessary with anti hypertensives such as beta blockers, calcium channel blockers ACE inhibitors.

Acute renal failure: The actual cause is not known although hypovolemia and sepsis has been implicated .Intrarenal factors have also been postulated to play a role. Renal failure may be secondary to bilateral renal vein thrombosis or interstitial nephritis. Acute renal failure is reversibile often with intravenous albumin and high dose frusemide on dialysis may be required.

\section{Steroid during Stress:}

Suppression of hypothalamopituitary axis may occur with prednisolone $>1 \mathrm{mg} / \mathrm{kg} /$ day for $>2$ weeks in the preceding 36 months. Stress doses of steroid, hydrocortisone $3050 \mathrm{mg} / \mathrm{m}^{2}$ or prednisolone I $\mathrm{mg} / \mathrm{kg} /$ day for the duration of stress is indicated.

\section{Conclusion:}

The prognosis of steroid sensitive nephrotic syndrome is excellent. The disease is characterized by relapses and remission. Education of parents and patients how to regularly monitor the urine and how to record the results in a diary is most important. 
The long term prognosis for most Children with steroid sensitive nephrotic syndrome (SSNS) is for resolution of their disease and maintenance of normal renal function. Approxemately $80 \%$ of children with SSNS will relapse one or more times. Of those, $50 \%$ relapse frequently or become steroid dependent. ${ }^{29}$

The frequency of relapses decreases with time with $50-70 \%$ of children being relapse-free at 5 years and about $85 \%$ relapse free at 10 years. $^{29}$

\section{References:}

1. Koskimes O. Long term outlook of primary nephrotic syndrome. Arch Dis Child 1982; 57: 544-8.

2. Trompeter RS, Lloyd BW, Hicks J, white RH, Cameron JS, Long term out come for children with minimal change riephrotic syndrome. Lancet 1985; 1: 368-70.

3. Kashagarian M, Hayslett JP, Seigel NJ. Lipoid nephrosis and focal sclerosis: distinct entities or spectrum of disease, Nephron 1974; 13: 105-108.

4. Sharples PM, poulton J, white RHN. Steroid responsive nephrotic syndrome is more common in Asians, Arch Dis child 1985; 60: 10141017

5. Ruley EJ Nephrotic syndrome in Hoekelman RA.Blatmans (eds): Primary Pediatric care st lous. Mosby year book 1987. p 1376-80.

6. Schnaper HW. The immune system in minimal change nephritic syndrome.Paediatric Nephrol 1989; 3: 101-10.

7. Schnaper HW.A regulatory system for soluble immune response suppressor production in steroid responsive nephritic syndrome. Kidney Int 1990; 38: 151-9.

8. Elises J S,Griffiths PD,Hoking MD,Taylor CM,White RHR. Simplified quantification of urinary protein excretion in children.Clin Nephrol 1988; 31: 225-9.

9. Consensus statement on management and audit potential for steroid responsive nephrotic syndrome Report of a workshop by the British Association for paediatric Nephrology and Research unit, Royal College of physicians. Arch Dis child 1994; 70: 151-7.

10. A report of the ISKDC.Nephrotic syndrome in children prediction of histopathology from clinical and laboratory charecteristic at time of diagnosis. Kidney International 1978; 13: 159-65.

11. Overturf GD.American Academy of pediatrics.Committee on Infectious Diseases. Technical report: prevention of pneumococcal infections, including pneumococcal Conjugate and polysaccharide vaccine and antibiotics prophylaxis. Paediatrics 2000; 106: 367-74.

12. Consensus statement on management and audit potential for steroid sensitive nephrotic syndrome. Report of a workshop by British association of paediatric nephrology.and research unit, Royal College of physician.1994; 70: 151-7.

13. Haws RM, Baum M. Efficacy of albumin and diuretic therapy in children with nephrotic syndrome. Paediatrics; 1993; 91: 1142-114.
14. A report of the ISKDC. The primary nephrotic syndrome in children. Identification of patients with minimal change nephrotic syndrome from initial response to prednisone J. Pediatrics; 1981; 98: 561-4.

15. Choonara IA, Henry D, Meadow SR. Low dose prednisolone in nephrotic syndrome. Arch Dis Child 1989; 64: 610-2

16. Brodehl J. Conventional therapy for idiopathic nephrotic syndrome. Clin Nephrol 1991; 35 (Suppl 1): S 8-15

17. Ueda N, Chihara M, Kawaguchi S et al. Intermittent versus long term tapering predrisolone for initial therapy in children with idiopathic nephrotic syndrome. J. Paediatr; 1988; 112-6.

18. Ksiazek J, Wyszynska T. Short versus long initial predrisone treatment in steroid sensitive nephrotic syndrome in children. Acta paediatr; 1995; 84: 889-93.

19. Joyantha UK. Comparison of ISKDC regeime with a 7 months steroid regeime at the first attack nephrotic syndrome. Paed. Nephrol 2004; 19: 81.

20. Hodson EM, Knight JF, Willis NS, Crag JC. Year 2005. Corticosteroid therapy for Nephrotic syndrome in children. The Cochrane data base of Systematic Reviews, Issue Art no: CD 001533. DOI 10.1002/1465 1858 CDO01. 1533.

21. Anonymous. Alternate-day versus intermittent prednisone in frequently relapsing nephrotic syndrome. A report of "Arbeitsgemeinschaft fur Padiatrische Nephrologie". Lancet 1979; 1: 401-3.

22. Immunosuppressive agents in childhood nephrotic syndrome: A metanalysis of randomized controlled trials, Arne M. Durkan, Elisabeth M. Hodson, Narelle S. willis, and Jonathan C. crais. Kidney international 2001; 59: 1919 -20.

23. Niaudet P, Broyer M, HabibR, 1991. Treatment of idiopathic nephrotic syndrome with cyclosporinA in children. Clin Nephrol 1991; 35 SUPPI I . S 3136.

24. Abeyagunawardena AS. Dillon MJ, Rees L,Hoff WV, Trompeter RS.The use of steroid sparing agent in steroid sensitive nephrotic syndrome. Paeditric Nephrol, 2003; 18: 919-24.

25. Grupe WE, Makker SP, Ingelfinger Chlorambucil treatment of frequently relapsing nephrotic syndrome. N Eng J Med; 1976; 295: 746-9.

26. AlSarsan K,Gisaru S, Stephans D, Arbus G.Levamisole Vs Cyclophosphamide for frequently relapsing steroid dependent nephrotic sundrome.Clin Nephrol 2001; 56: 28994.

27. Patric Niaudet. Steroid sensitive Nephrotic syndrome in Children. Paediatric Nephrology 5th edition. Lippincott willams and wilkins. Maple press,Philadelphia 2006. p 543556.

28. Geoge Haycock.The Child with Ideopathic nephroric syndrome.In: Nicholas JA.,Webb and Robert J. Postlethwaite editors.Clinical Paediatric Naphrology.3rd edition.Oxford University Press; 2003.p 341-366.

29. Tarshist P, Tobin JN,Bernstein J,Edelmann CMJ. Prognostic Significance of the early course of minimal change Disease in Children. J Am soc Nephrol 1997; 8: 769-776. 